\title{
Development of Colonic Perforation during Calcium Polystyrene Sulfonate Administration: A Case Report
}

\author{
Nobuhiro Takeuchi, ${ }^{1}$ Yusuke Nomura, ${ }^{1}$ Testuo Meda, ${ }^{1}$ Masato Iida, \\ Akihito Ohtsuka, ${ }^{1}$ and Kazuyoshi $\mathrm{Naba}^{2}$ \\ ${ }^{1}$ Department of Internal Medicine, Kawasaki Hospital, 3-3-1 Higashiyama-cho, Kobe, Hyogo 652-0042, Japan \\ ${ }^{2}$ Department of Laboratory Medicine, Kawasaki Hospital, 3-3-1 Higashiyama-cho, Kobe, Hyogo 652-0042, Japan \\ Correspondence should be addressed to Nobuhiro Takeuchi; takeuchi_nobuhiro@kawasaki-hospital-kobe.or.jp
}

Received 4 October 2013; Accepted 1 November 2013

Academic Editor: Bruno Megarbane

Copyright (C) 2013 Nobuhiro Takeuchi et al. This is an open access article distributed under the Creative Commons Attribution License, which permits unrestricted use, distribution, and reproduction in any medium, provided the original work is properly cited.

\begin{abstract}
A 90-year-old female complaining of severe upper abdominal pain was transferred to our institution. The patient had been prescribed with calcium polystyrene sulfonate (CPS) for the treatment of hyperkalemia following myeloperoxidase-antineutrophil cytoplasmic antibody (MPO-ANCA) associated glomerulonephritis. Physical examination revealed diffuse tenderness over the abdomen, with signs of peritoneal irritation. Abdominal computed tomography (CT) revealed the retention of ascites, free air in the abdominal cavity, and the retention of hard stools in the left-sided colon. The diagnosis of intestinal perforation was immediately confirmed; thereafter, the patient underwent emergency surgical treatment. Surgical findings revealed a perforated site in the descending colon surrounded with hard stools. Histopathology of the perforated colon revealed crystalline materials, suggestive of association with CPS. CPS is a cation-exchange resin used to treat hyperkalemia; the major adverse effect in patients receiving CPS is constipation. When CPS is administered to patients with frequent constipation or the elderly, the risk of intestinal perforation should be considered.
\end{abstract}

\section{Introduction}

Calcium polystyrene sulfonate (CPS) is a cation-exchange resin widely used in the treatment of hyperkalemia associated with acute or chronic renal failure; however, the major side effect of CPS is constipation. Here we describe the case of a 90 -year-old female who presented with colonic perforation during CPS administration.

\section{Case Presentation}

A 90-year-old female complaining of severe upper abdominal pain was transferred to our institution in December 2012. The patient's history included angina pectoris, which was treated using coronary stents and dual antiplatelet therapy. The patient was treated with hemodialysis for myeloperoxidaseantineutrophil cytoplasmic antibody (MPO-ANCA) associated glomerulonephritis and had been receiving CPS (ARGAMATE) for the treatment of hyperkalemia. On admission, the patient was confirmed to be in shock with the following signs: blood pressure, $77 / 55 \mathrm{~mm} \mathrm{Hg}$; heart rate, 82 beats/min; body temperature, $36.5^{\circ} \mathrm{C}$; oxygen saturation, $92 \%$ on room air. On clinical examination, her weight, height, and body mass index were $40.6 \mathrm{~kg}, 139 \mathrm{~cm}$, and $20.9 \mathrm{~kg} / \mathrm{m}^{2}$, respectively. Inspection of the palpebral conjunctiva revealed evidence of severe anemia. Chest auscultation revealed no evidence of abnormal heart murmurs and no rales or other lung sounds. The abdomen revealed diffuse tenderness, with signs of peritoneal irritation. Physical examination revealed whole body cyanosis. Blood chemical analyses (Table 1) revealed markedly decreased white blood cell counts $(1600 / \mu \mathrm{L}$ ), severe anemia (red blood cell counts: $234 \times 10^{4} / \mu \mathrm{L}$; hemoglobin levels, $7.9 \mathrm{~g} / \mathrm{dL}$ ), severely decreased platelet counts $\left(6.0 \times 10^{4} / \mu \mathrm{L}\right)$, increased serum urea nitrogen levels $(39.3 \mathrm{mg} / \mathrm{dL})$, markedly increased serum creatinine levels $(5.35 \mathrm{mg} / \mathrm{dL})$, severe hypoproteinemia $(3.5 \mathrm{~g} / \mathrm{dL})$, severe hypoalbuminemia $(3.0 \mathrm{~g} / \mathrm{dL})$, increased glucose levels $(199 \mathrm{mg} / \mathrm{dL})$, increased brain natriuretic 
TABLE 1: Laboratory data on admission.

\begin{tabular}{|c|c|}
\hline \multicolumn{2}{|l|}{ Hematology } \\
\hline WBC & $1,600 / \mu \mathrm{L}$ \\
\hline $\mathrm{RBC}$ & $234 \times 10^{4} / \mu \mathrm{L}$ \\
\hline $\mathrm{Hb}$ & $7.9 \mathrm{~g} / \mathrm{dL}$ \\
\hline $\mathrm{Ht}$ & $23.0 \%$ \\
\hline PLT & $6.0 \times 10^{4} / \mu \mathrm{L}$ \\
\hline \multicolumn{2}{|l|}{ Coagulation } \\
\hline $\mathrm{PT}$ & $68 \%$ \\
\hline PT-INR & 3.93 \\
\hline Fib & $126 \mathrm{mg} / \mathrm{dL}$ \\
\hline FDP & $15.6 \mu \mathrm{g} / \mathrm{mL}$ \\
\hline D-dimer & $3.9 \mu \mathrm{g} / \mathrm{mL}$ \\
\hline \multicolumn{2}{|c|}{ Blood chemistry } \\
\hline $\mathrm{TP}$ & $3.5 \mathrm{~g} / \mathrm{dL}$ \\
\hline Alb & $3.0 \mathrm{~g} / \mathrm{dL}$ \\
\hline T-Bil & $0.6 \mathrm{mg} / \mathrm{dL}$ \\
\hline$\gamma$-GTP & $7 \mathrm{IU} / \mathrm{L}$ \\
\hline AST & $21 \mathrm{IU} / \mathrm{L}$ \\
\hline ALT & $11 \mathrm{IU} / \mathrm{L}$ \\
\hline $\mathrm{LDH}$ & $111 \mathrm{IU} / \mathrm{L}$ \\
\hline BUN & $39.3 \mathrm{mg} / \mathrm{dL}$ \\
\hline $\mathrm{Cr}$ & $5.35 \mathrm{mg} / \mathrm{dL}$ \\
\hline $\mathrm{Na}$ & $136 \mathrm{mEq} / \mathrm{L}$ \\
\hline $\mathrm{K}$ & $4.0 \mathrm{mEq} / \mathrm{L}$ \\
\hline $\mathrm{Cl}$ & $106 \mathrm{mEq} / \mathrm{L}$ \\
\hline $\mathrm{BNP}$ & $299.0 \mathrm{pg} / \mathrm{mL}$ \\
\hline \multicolumn{2}{|l|}{ Sugar } \\
\hline Glucose & $191 \mathrm{mg} / \mathrm{dL}$ \\
\hline \multicolumn{2}{|c|}{ Blood gas analysis } \\
\hline & (Room air) \\
\hline $\mathrm{pH}$ & 7.375 \\
\hline $\mathrm{PaCO}_{2}$ & $34.5 \mathrm{mmHg}$ \\
\hline $\mathrm{PaO}_{2}$ & $72.9 \mathrm{mmHg}$ \\
\hline $\mathrm{HCO}_{3}^{-}$ & $19.7 \mathrm{mmol} / \mathrm{L}$ \\
\hline $\mathrm{BE}$ & $-4.6 \mathrm{mmol} / \mathrm{L}$ \\
\hline
\end{tabular}

peptide levels $(299.0 \mathrm{pg} / \mathrm{mL})$, mildly increased C-reactive protein levels $(1.0 \mathrm{mg} / \mathrm{dL})$, and coagulation dysfunction (prothrombin time, 18\%; fibrin/fibrinogen degradation products, $15.6 \mu \mathrm{g} / \mathrm{mL}$; D-dimer levels, $3.9 \mu \mathrm{g} / \mathrm{mL}$ ). Blood gas analyses revealed mild metabolic acidosis (bicarbonate ion carbonic acid, $19.7 \mathrm{mmol} / \mathrm{mL}$; base excess, $-4.6 \mathrm{mmol} / \mathrm{L}$ ). Chest and abdominal radiography revealed free air under bilateral diaphragms, suggesting intestinal perforation (Figures 1(a) and 1(b)). Abdominal computed tomography (CT) revealed the presence of ascites, free air in the abdominal cavity, and the retention of hard stools in the left-sided colon (Figures 2(a) and 2(b)). The diagnosis of intestinal perforation was immediately confirmed; subsequently, the patient underwent emergency surgical treatment. Surgical findings (Figures 3(a) and 3(b)) revealed a $55 \times 22 \mathrm{~mm}$ perforated site in the middle of the descending colon surrounded with hard stools. No diverticulum was evident in the colon. The descending colon, including the affected site, was resected, and a colostomy was created in the transverse colon. Histopathology of the perforated colon revealed basophilic polygonal crystalline materials, which suggested the association of CPS with this perforation (Figure 4(a)). Crystalline materials were negative for PAS, Ziehl-Neelsen, and Congo-red stains (Figures 4(b), 4(c), and $4(\mathrm{~d})$ ). The postoperative course was eventful: the patient went into septic shock and developed acute respiratory distress as well as multiple organ failure. The patient eventually died of panperitonitis on day 3 of admission.

\section{Discussion}

CPS is a cation-exchange resin used in the treatment of hyperkalemia associated with acute or chronic renal failure. Both ARGAMATE (jelly type) and KALIMATE (powder type) contain CPS. The major adverse effect of CPS is constipation. Several cases treated with CPS require purgatives: CPS has been used with a combination of sorbitol liquid, an osmotic purgative. Some authors [1-3] have reported cases that developed intestinal necrosis induced by combined administration of CPS and the sorbitol liquid. Further, colonic ischemia or perforation associated with the combined anal administration of CPS and the sorbitol liquid occurred in approximately $1 \%$ of cases [4]. Thereafter, the combined use of CPS and sorbitol was warned. Although the use of CPS alone is permitted, single use of CPS may also cause intestinal necrosis [5].

In patients with chronic renal failure undergoing hemodynamic dialysis (HD), the presence of chronic intestinal inflammation induced by intestinal ischemia should be considered. The renin-angiotensin system (RAS) activated by hypotension following $\mathrm{HD}$, uremia, or hypovolemia may cause vasospasms that include mesenteric vessels, thereby leading to intestinal necrosis and nonobstructive mesenteric ischemia. Under this condition, vulnerable intestinal mucosa may be more easily perforated by hard stools resulting from CPS. Few authors reported a case of direct invasion of CPS from the inflamed intestinal mucosa into the tissue; the vulnerable intestinal mucosa of patients undergoing HD for renal failure was considered as one of the reasons. However, in this case, histopathology of resected specimens revealed no chronic intestinal inflammation caused by vasculitis, thrombus, or ischemic change. Indeed, chronic intestinal inflammation is not very specific as such, and it is not the only sign of the conditions mentioned above. A direct mechanical effect of hard stools following CPS administration may have triggered the colonic perforation in this elderly patient with several comorbidities including old age, poor vascular supply, chronic renal insufficiency, hard stools, and a possible toxic effect of drugs. In the present case, ARGAMATE intake may have worsened the constipation, and a hard stool may have perforated the descending colon. Moreover, the patient lacked dietary fiber because of strict limitations of potassium and fluid intake, which may have aggravated the constipation as well.

Microscopic examination of ARGAMATE revealed crystalline fiber materials recognized as CPS (Figures 5(a) and 5(b)). On histopathological analysis, crystalline materials 


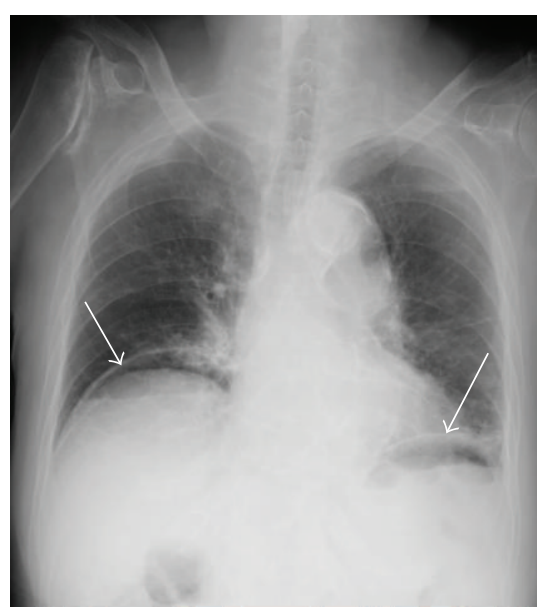

(a)

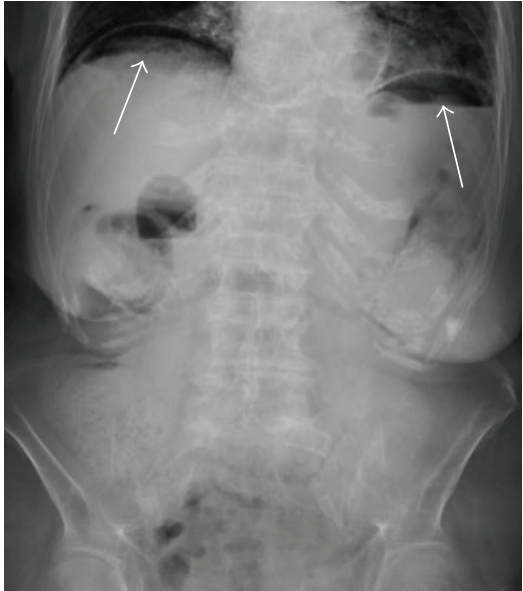

(b)

FIGURE 1: Chest (a) and abdominal (b) radiography revealed free air under bilateral diaphragms.

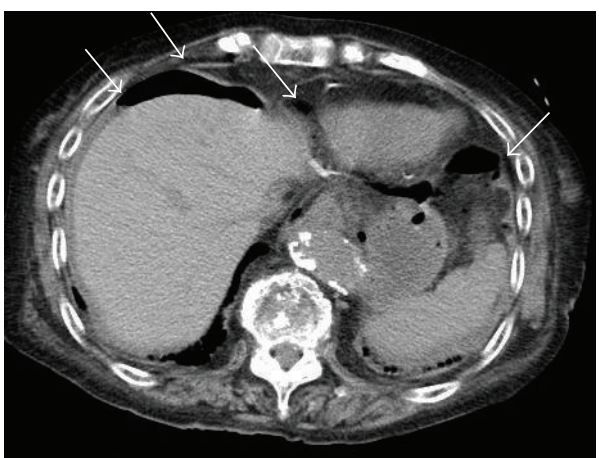

(a)

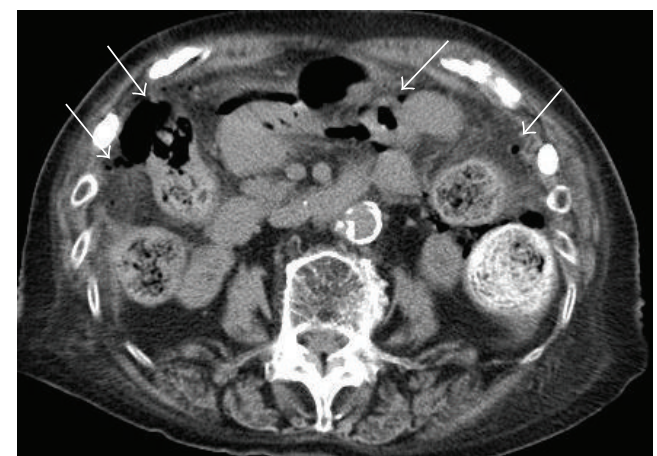

(b)

FiguRE 2: Abdominal computed tomography revealed the presence of ascites, free air in the abdominal cavity, and hard stools in the left-sided colon ((a), (b)).

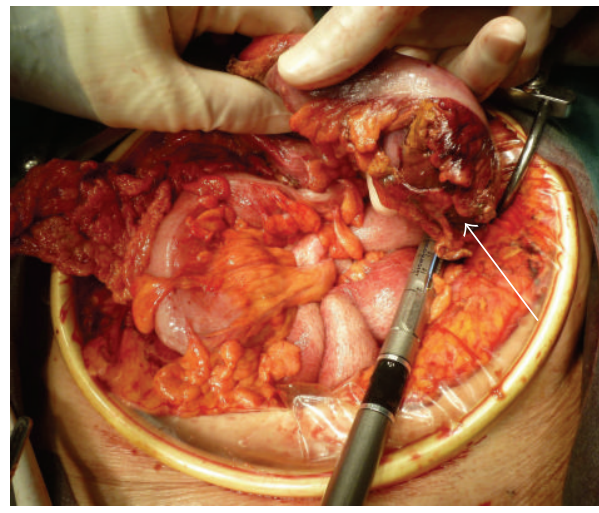

(a)

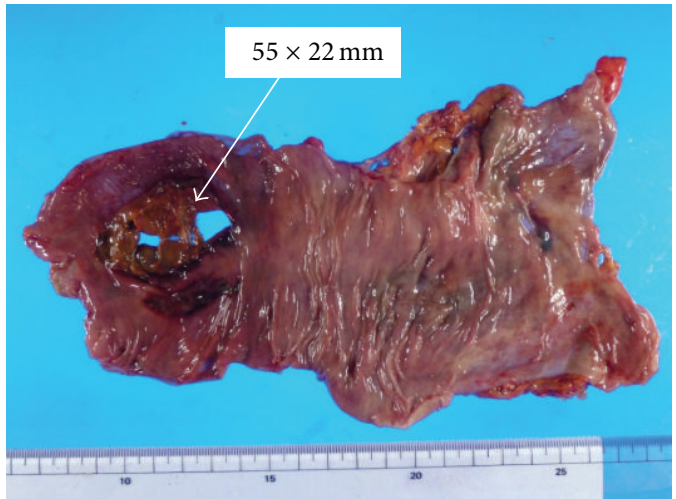

(b)

FIGURE 3: Surgical findings revealed a perforated site in the descending colon surrounded with hard stools ((a), (b)).

were observed to be scattered around the perforated site following intestinal perforation. The mechanism of this perforation may be similar to that of stercoral colonic perforation. Moreover, crystalline materials were not evident in the nonperforated site of the descending colon suggesting that
ARGAMATE directly affected intestines. In most cases, when ARGAMATE causes intestinal perforation, the common site of involvement is the left-sided colon. As intestinal contents move forward to the anus, water is absorbed in intestines and harder stools harden because of the resin; therefore, 


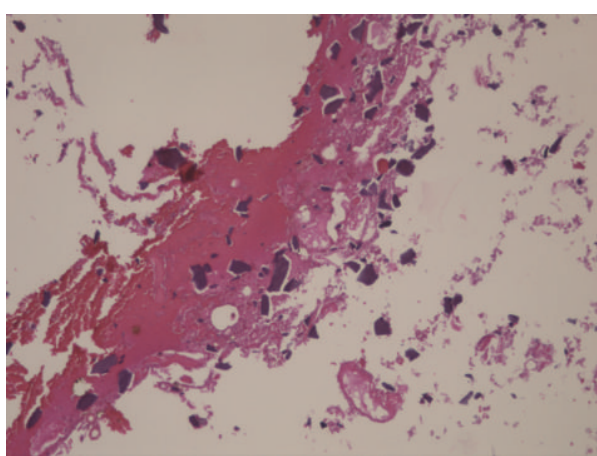

(a)

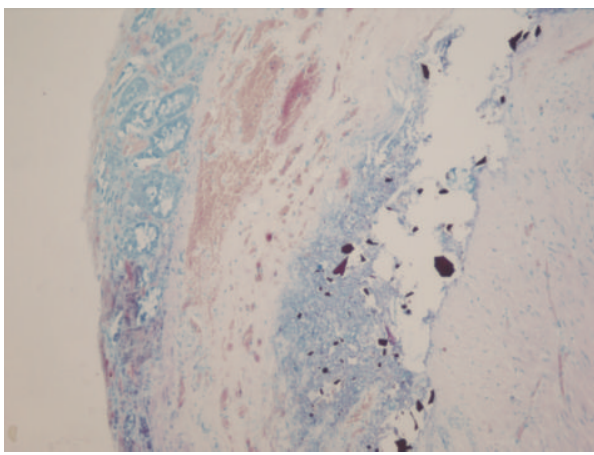

(c)

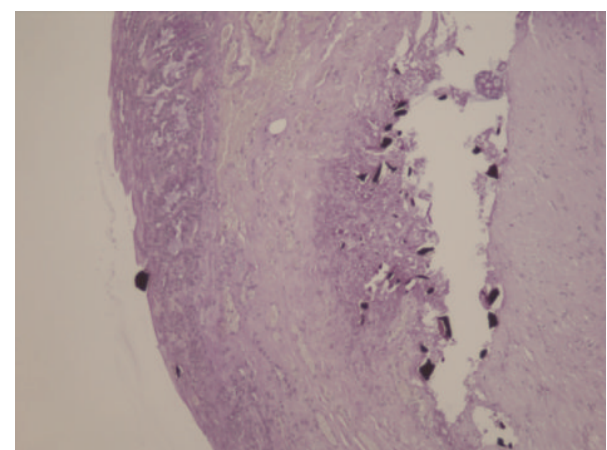

(b)

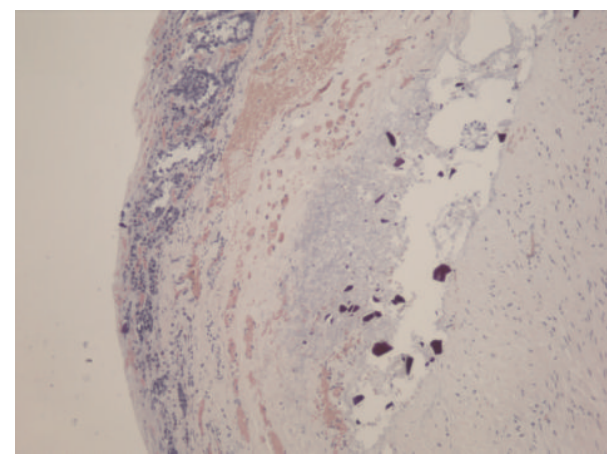

(d)

FIGURE 4: Several basophilic polygonal crystalline materials were found on hematoxylin and eosin staining (a), and crystalline materials were negative on PAS (b), Ziehl-Neelsen (c), and Congo-red stains (d).

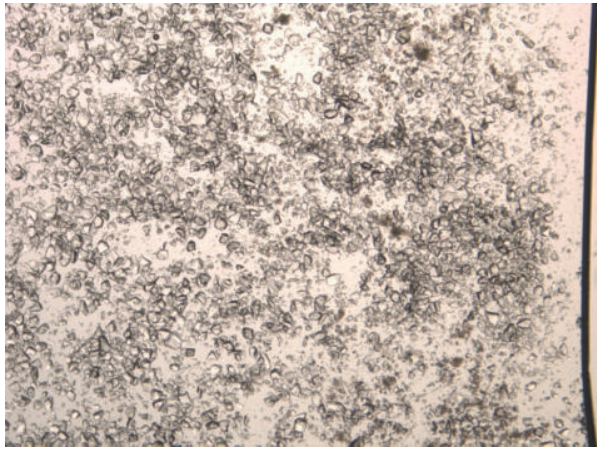

(a)

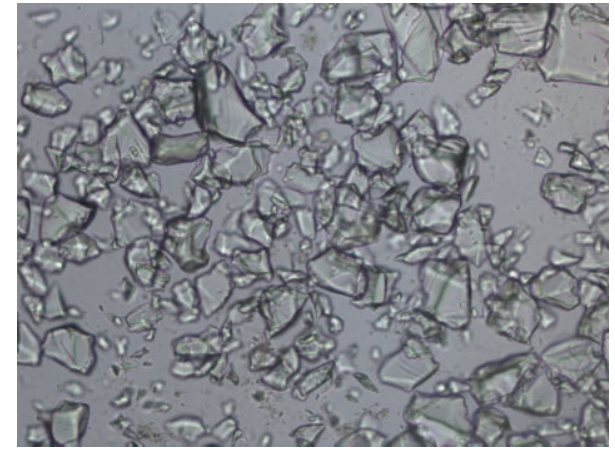

(b)

FIGURE 5: Microscopic examination of ARGAMATE revealed crystalline materials ((a) low power field, (b) high power field).

extremely hard stools are formed in the left-sided colon, including the descending colon, sigmoid colon, and rectum. Moreover, the left-sided colon has several curved portions causing stool obstruction toward the anus. With stagnation of harder stools, colonic pressure increases, leading to colonic perforation or necrosis. Although the possibility remains that ARGAMATE could be the cause of intestinal perforation, there are no reports to date indicating that ARGAMATE causes perforation of the small intestine; therefore, there is no evidence to support this idea.

A previous study reported the [6] use of CPS used in a patient with small intestinal diverticulosis, which led to small intestinal perforation; therefore, the retention and accumulation of CPS in the diverticula may cause direct mucosal damage. In the present case, colonic diverticulosis was not evident in either imaging or surgical findings. Nevertheless, the colonic diverticulum should be observed by imaging or endoscopy before initiating CPS administrations.

\section{Conclusions}

Here we report the case of a 90-year-old female who presented with colonic perforation during CPS administration. 
When CPS is administered to patients with frequent constipation or the elderly, the risk of intestinal perforation should be considered.

\section{References}

[1] K. D. Lillemoe, J. L. Romolo, and S. R. Hamilton, "Intestinal necrosis due to sodium polystyrene (Kayexalate) in sorbitol enemas: clinical and experimental support for the hypothesis," Surgery, vol. 101, no. 3, pp. 267-272, 1987.

[2] M. Watson, K. C. Abbott, and C. M. Yuan, "Damned if you do, damned if you don't: potassium binding resins in hyperkalemia," Clinical Journal of the American Society of Nephrology, vol. 5, no. 10, pp. 1723-1726, 2010.

[3] R. H. Sterns, M. Rojas, P. Bernstein, and S. Chennupati, "Ionexchange resins for the treatment of hyperkalemia: are they safe and effective?" Journal of the American Society of Nephrology, vol. 21, no. 5, pp. 733-735, 2010.

[4] A. Rashid and S. R. Hamilton, "Necrosis of the gastrointestinal tract in uremic patients as a result of sodium polystyrene sulfonate (kayexalate) in sorbitol: an underrecognized condition," The American Journal of Surgical Pathology, vol. 21, no. 1, pp. 60-69, 1997.

[5] S. Fujitake, H. Uchida, A. Takikawa et al., "An elderly case of colonic perforation associated with orally administered calcium polystyrene sulfonate," Journal of Japanese Society for Emergency Medicine, vol. 11, pp. 443-448, 2008.

[6] M. Pusztaszeri, M. Christodoulou, S. Proietti, and W. Seelentag, "Kayexalate intake (in sorbitol) and jejunal diverticulitis, a causative role or an innocent bystander?" Case Reports in Gastroenterology, vol. 1, pp. 144-151, 2007. 


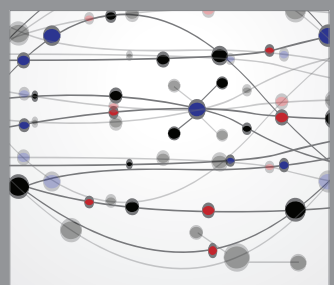

The Scientific World Journal
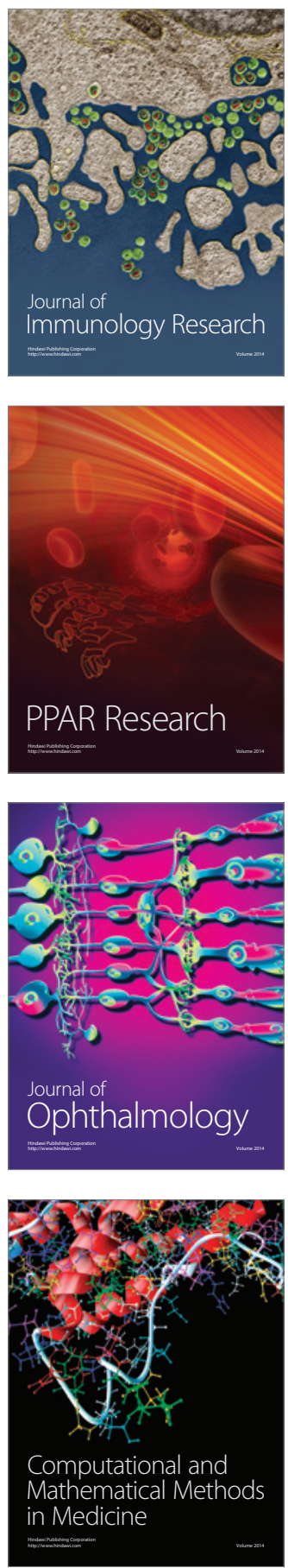

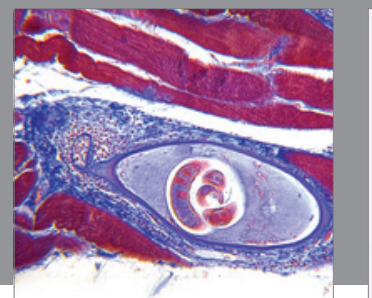

Gastroenterology

Research and Practice
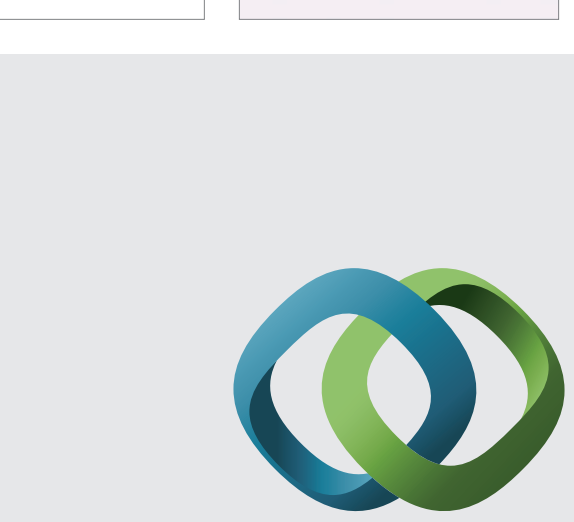

\section{Hindawi}

Submit your manuscripts at

http://www.hindawi.com
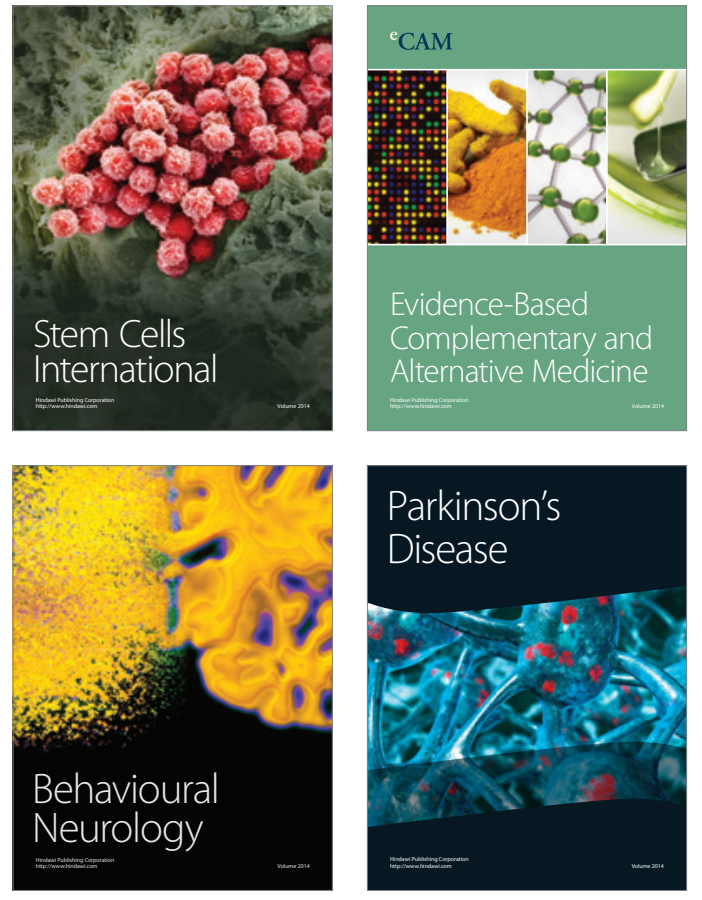
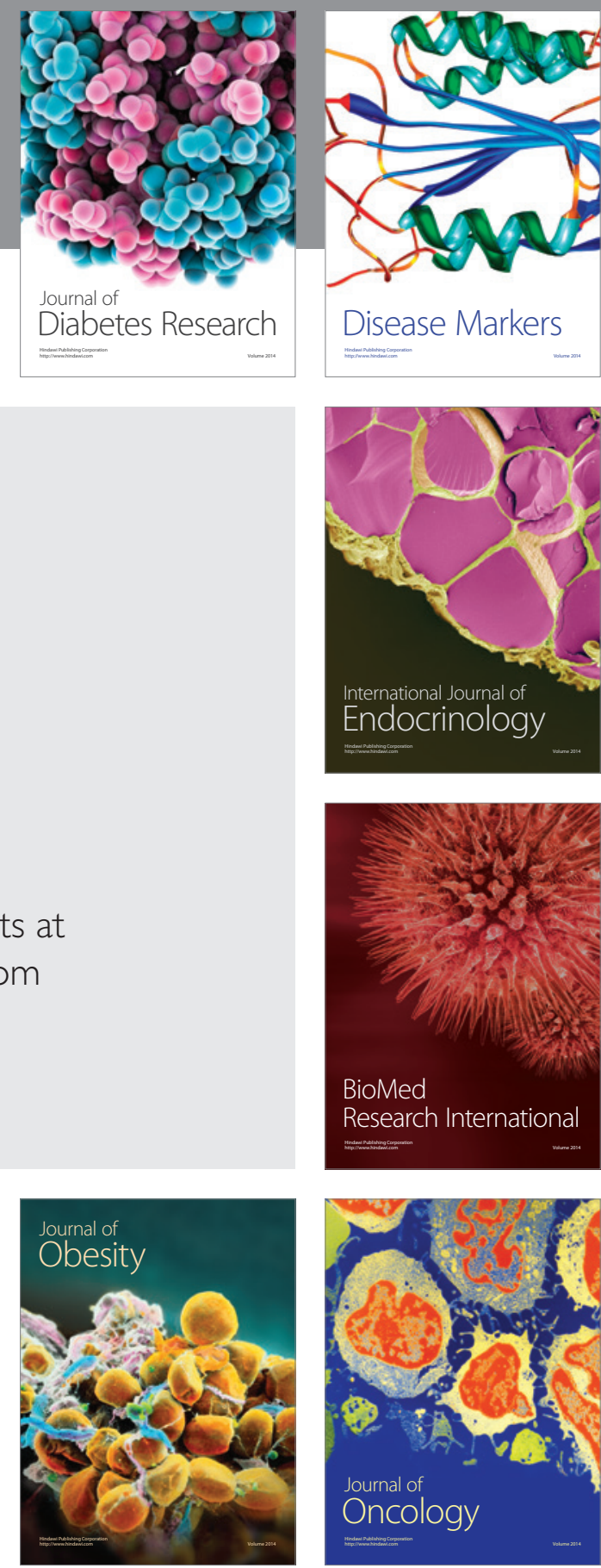

Disease Markers
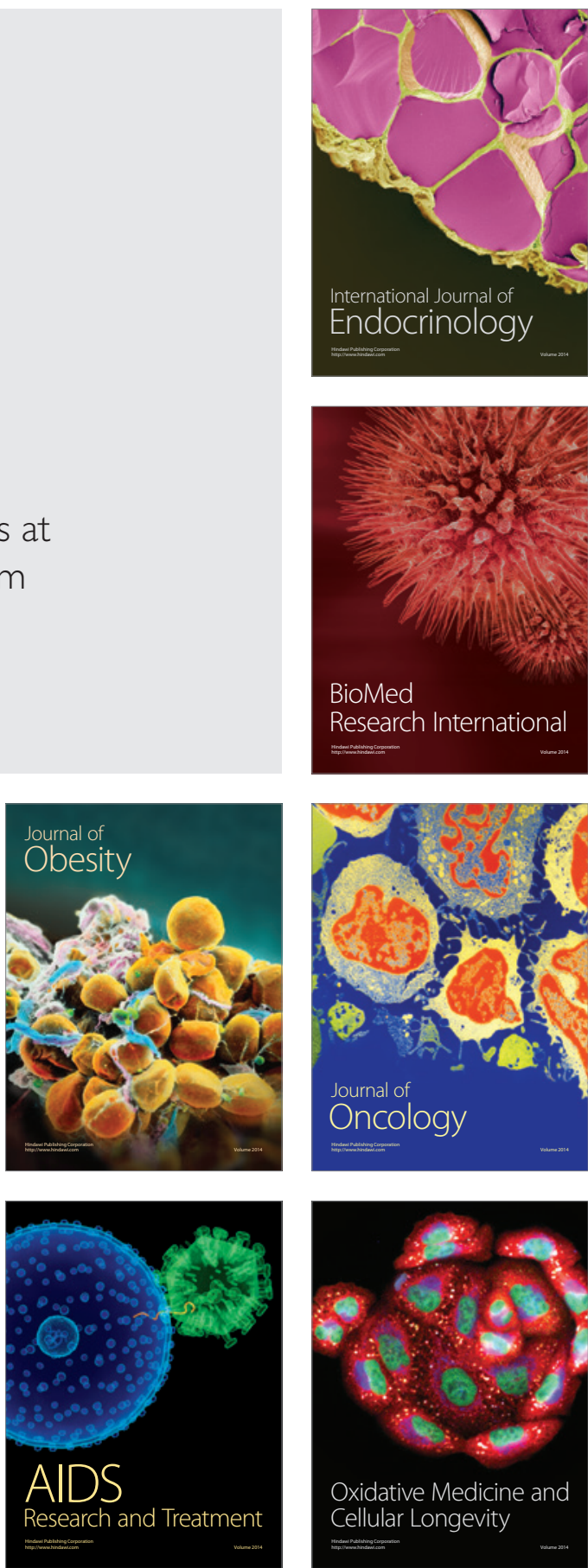